\title{
Postnatal Administration of Allopregnanolone Modifies Glutamate Release but Not BDNF Content in Striatum Samples of Rats Prenatally Exposed to Ethanol
}

\author{
Roberto Yunes, ${ }^{1,2}$ Cecilia R. Estrella, ${ }^{1}$ Sebastián García, ${ }^{1,2}$ \\ Hernán E. Lara, ${ }^{3}$ and Ricardo Cabrera ${ }^{1}$ \\ ${ }^{1}$ Instituto de Investigaciones Biomédicas (INBIOMED-IMBECU-CONICET), Facultad de Ciencias de la Salud, \\ Universidad de Mendoza, Paseo Dr. Emilio Descotte 720, 5500 Mendoza, Argentina \\ ${ }^{2}$ Área de Farmacología, Facultad de Ciencias Médicas, Universidad Nacional de Cuyo, Avenidad del Libertador 80, \\ 5500 Mendoza, Argentina \\ ${ }^{3}$ Laboratorio de Neurobioquímica, Facultad de Ciencias Químicas y Farmacéuticas, Universidad de Chile, \\ Calle Sergio Livingstone Polhammer 1007, 8380492 Santiago de Chile, Chile
}

Correspondence should be addressed to Ricardo Cabrera; rcabrera@mendoza-conicet.gob.ar

Received 15 December 2014; Revised 10 February 2015; Accepted 11 February 2015

Academic Editor: Abdel A. Abdel-Rahman

Copyright (C) 2015 Roberto Yunes et al. This is an open access article distributed under the Creative Commons Attribution License, which permits unrestricted use, distribution, and reproduction in any medium, provided the original work is properly cited.

Ethanol consumption during pregnancy may induce profound changes in fetal CNS development. We postulate that some of the effects of ethanol on striatal glutamatergic transmission and neurotrophin expression could be modulated by allopregnanolone, a neurosteroid modulator of $\mathrm{GABA}_{\mathrm{A}}$ receptor activity. We describe the acute pharmacological effect of allopregnanolone $(65 \mu \mathrm{g} / \mathrm{kg}$, s.c.) administered to juvenile male rats (day 21 of age) on the corticostriatal glutamatergic pathway, in both control and prenatally ethanol-exposed rats (two ip injections of $2.9 \mathrm{~g} / \mathrm{kg}$ in $24 \% \mathrm{v} / \mathrm{v}$ saline solution on gestational day 8). Prenatal ethanol administration decreased the $\mathrm{K}^{+}$-induced release of glutamate regarding the control group. Interestingly, this effect was reverted by allopregnanolone. Regarding BDNF, allopregnanolone decreases the content of this neurotrophic factor in the striatum of control groups. However, both ethanol alone and ethanol plus allopregnanolone treated animals did not show any change regarding control values. We suggest that prenatal ethanol exposure may produce an alteration of $\mathrm{GABA}_{\mathrm{A}}$ receptors which blocks the GABA agonist-like effect of allopregnanolone on rapid glutamate release, thus disturbing normal neural transmission. Furthermore, the reciprocal interactions found between GABAergic neurosteroids and BDNF could underlie mechanisms operating during the neuronal plasticity of fetal development.

\section{Introduction}

Maternal alcohol consumption during pregnancy induces profound changes in the development of the central nervous system (CNS) in offspring [1]. Although the most critical birth defect associated with alcohol consumption is fetal alcohol syndrome (FAS) [2], many children who were prenatally exposed to alcohol do not present the morphological brain changes characteristically seen in FAS, yet they may still exhibit many of the mental dysfunctions induced by ethanol [3]. Problems characteristically associated with this pathology include impaired cognitive and motor skills, with a reduction in general intellectual functioning, deficits in verbal learning, spatial memory, and reasoning [4].

The basal ganglia appear to be sensitive to prenatal ethanol exposure, as they are clearly smaller in children that suffer from FAS [1]. The corpus striatum, a component of the basal ganglia, is a critical brain structure involved in motor, perceptual, and cognitive skills $[5,6]$. It is innervated by excitatory glutamatergic and inhibitory GABAergic neurons. 
The function of these nerve terminals is finely modulated by neurotransmitters and by neurotrophic factors acting on their specific receptors, the expression of which is altered by prenatal exposure to ethanol $[7,8]$. Although the most common way to stimulate the receptors for glutamate and GABA is the ligands themselves, an interesting kind of molecules called neurosteroids may act as modulators of ion channels-coupled receptors and thereby also mediate neuronal responses $[9,10]$.

Recently, neurosteroids have received much attention as neuroprotective agents against different injuries affecting the CNS [11]. These effects could be modulated, among others, via neuromodulation of GABAergic transmission and less directly by modifying neurotrophin expression, a notion supported by the fact that inducible neurotrophins are downregulated by GABA activity [12]. Recent research shows that allopregnanolone ( $3 \alpha$-hydroxy- $5 \alpha$-pregnan-20one), a potent positive modulator of $\mathrm{GABA}_{\mathrm{A}}$ and glutamate receptors activity [13], brain concentration is particularly affected by ethanol administrations in rats [14]. Also, nerve growth factor (NGF) and brain-derived neurotrophic factor (BDNF), members of the neurotrophin family, protect neurons from insults and regulate synaptic transmission in the corpus striatum $[15,16]$.

Previous reports show that acute ethanol intoxication of rat embryos on gestational day 8 produces postnatal impairments in the neuronal function $[17,18]$. In this study we work with a similar experimental paradigm, ethanol intoxication of rat embryos on gestational day 8 , in order to study potential modifications of glutamatergic and GABAergic neurotransmission. We postulate that the neurosteroid allopregnanolone administered on postnatal day 21 can possibly override the damaging effect of ethanol by (1) interaction of the neurosteroid allopregnanolone with glutamatergic and GABAergic systems in striatum and (2) modifications of expression of the neurotrophin BDNF. Both results allow us to postulate the use of neurosteroids as potentially useful molecules in neuroregeneration after brain damage induced by prenatal ethanol exposure.

\section{Materials and Methods}

2.1. Reagents. The used reagents were as follows: ethanol (Biofarma); allopregnanolone (Sigma, St. Louis, MO, USA); $\left({ }^{3} \mathrm{H}\right)$-glutamic acid $\left({ }^{3} \mathrm{H}\right.$-Glu $) ;\left({ }^{3} \mathrm{H}\right)-\gamma$-aminobutyric acid $\left({ }^{3} \mathrm{H}\right.$ GABA) (New England Nuclear (Boston, MA, USA)); carbogen $\left(95 \% \mathrm{O}_{2}\right.$ and $\left.5 \% \mathrm{CO}_{2}\right)$ Krebs-Ringer bicarbonate glucose buffer (KRB, pH 7.4) or $\mathrm{Mg}^{2+}$-free KRB (experiments with $\left.{ }^{3} \mathrm{H}-\mathrm{Glu}\right)$; BDNF Emax ImmunoAssay System kits from Promega (Madison, WI, USA).

2.2. Animals and Prenatal Exposure to Ethanol. The procedure used to expose rats to ethanol on gestational day 8 (GD8) has been previously described [19]. Adult male and female Sprague-Dawley rats (280-300 g) from our own breeding colony were used. Animals for these experiments were kept and handled according to the Guide for the Care and Use of Laboratory Animals, Institute of Laboratory Animal
Research, Commission on Life Sciences, National Research Council, USA [20]. All efforts were made to minimize animal suffering. They were housed under a constant temperature of $22 \pm 1^{\circ} \mathrm{C}$ and a standard light/dark cycle (12 h light schedule lights on at 07:00 a.m.) and controlled environment with food and water ad libitum. Samples for vaginal smears were taken daily from 09:00 to 10:00 a.m. Only rats that showed more than two normal 4-5-day consecutive estrus cycles were used for the experiments. On the evening of proestrus, they were housed overnight with male rats. Presence of spermatozoa in vaginal smears the following morning was interpreted as an index of pregnancy and was referred to as gestational day 1 (GD1). On GD8 animals were randomly divided into two groups: one of them received two intraperitoneal (ip) injections of ethanol $(2.9 \mathrm{~g} / \mathrm{kg}$ in $24 \% \mathrm{v} / \mathrm{v}$ saline solution), spaced by an interval of $4 \mathrm{~h}$, and the other one received an identical volume of the saline, also spaced by a $4 \mathrm{~h}$ interval (control). Delivery day was considered as postnatal day 1 (P1). All litters were normalized to $10-12$ pups/rat and were maintained until postnatal day 21 (P21). On P21 only male pups were selected for the experimental protocol.

2.3. Neurosteroid Treatment. On P21, ethanol and control males pups $(n=6-9)$ were s.c. injected with allopregnanolone $(65 \mu \mathrm{g} / \mathrm{kg})$ dissolved in propylene glycol $(0.2 \mathrm{mg} / \mathrm{mL})$ or with the same volume of vehicle. Allopregnanolone was initially dissolved in propylene glycol to a concentration of $600 \mu \mathrm{M}$. The dose of allopregnanolone used in the experiments $(65 \mu \mathrm{g} / \mathrm{kg})$ was obtained by successive dilution in sterile saline. We selected this dose because it is approximately two hundred times higher than in serum concentration obtained in the night of proestrus in intact female rats [21]. After $2.5 \mathrm{~h}$ they were decapitated and the brains were rapidly removed. The corpus striatum was immediately dissected out on ice for release experiments. For neurotrophin content measures, the striatum was removed and stored at $-80^{\circ} \mathrm{C}$ until the day of the measurement procedure.

2.4. Release Experiments. Dissected striatal samples from 6-9 rats were sliced at $240 \mu \mathrm{m}$ with a McIlwain tissue chopper and 6 to 8 slices (experimental tissue) were exposed to $2.79 \mu \mathrm{M}$ $\left({ }^{3} \mathrm{H}\right)$-glutamic acid $\left({ }^{3} \mathrm{H}-\mathrm{Glu}\right)$ (specific activity $\left.44 \mathrm{Ci} / \mathrm{mmol}\right)$ or $940 \mathrm{nM}\left({ }^{3} \mathrm{H}\right)-\gamma$-aminobutyric acid $\left({ }^{3} \mathrm{H}\right.$-GABA) (specific activity $93.20 \mathrm{Ci} / \mathrm{mmol})$ in $2 \mathrm{~mL}$ of gassed $\left(95 \% \mathrm{O}_{2}\right.$ and $5 \% \mathrm{CO}_{2}$ ) Krebs-Ringer bicarbonate glucose buffer (KRB, $\mathrm{pH}$ 7.4) or $\mathrm{Mg}^{2+}$-free $\mathrm{KRB}$ (experiments with ${ }^{3} \mathrm{H}-\mathrm{Glu}$ ), for $15 \mathrm{~min}$ at $37^{\circ} \mathrm{C}$. Slices were transferred to perfusion chambers and superfused at a flow rate of $0.7 \mathrm{~mL} / \mathrm{min}$ with $\mathrm{KRB}$ for $30 \mathrm{~min}$ to remove nonincorporated neurotransmitter (washing period). After that 5 fractions of samples (2 min each) were collected and considered as basal release. Thereafter, a depolarizing concentration of $\mathrm{K}^{+}(\mathrm{KCl} 28 \mathrm{mM})$ was introduced by addition in the superfusion system for a $6 \mathrm{~min}$ period. Fractions collected during this time were considered as stimulated release. At the end of the experiment, slices were homogenized in $2 \mathrm{~mL} 0.2 \mathrm{~N}$ perchloric acid in order to obtain the total amount of radioactivity loaded by the tissue. Aliquots of $500 \mu \mathrm{L}$ of the samples and homogenized tissue were mixed with scintillation solution. The radioactivity of 


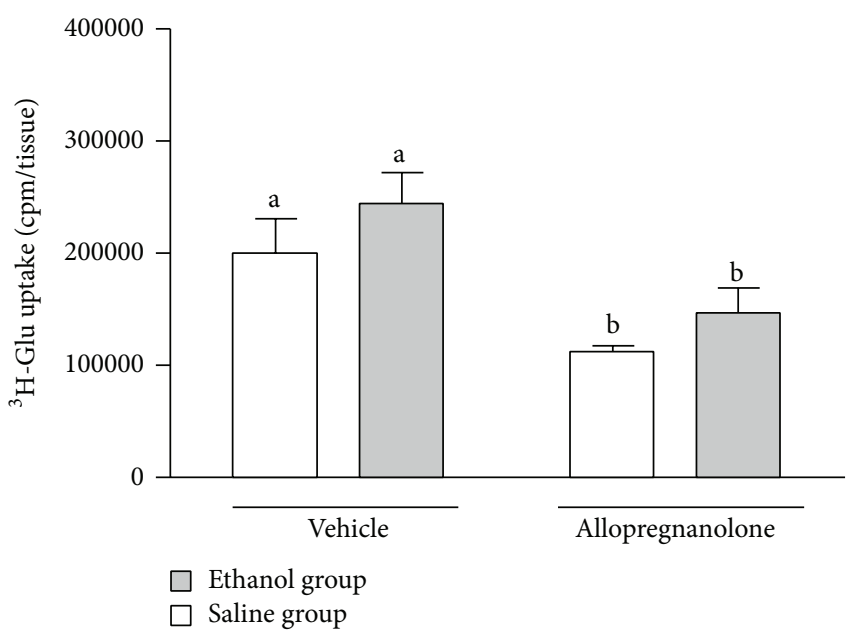

(a)

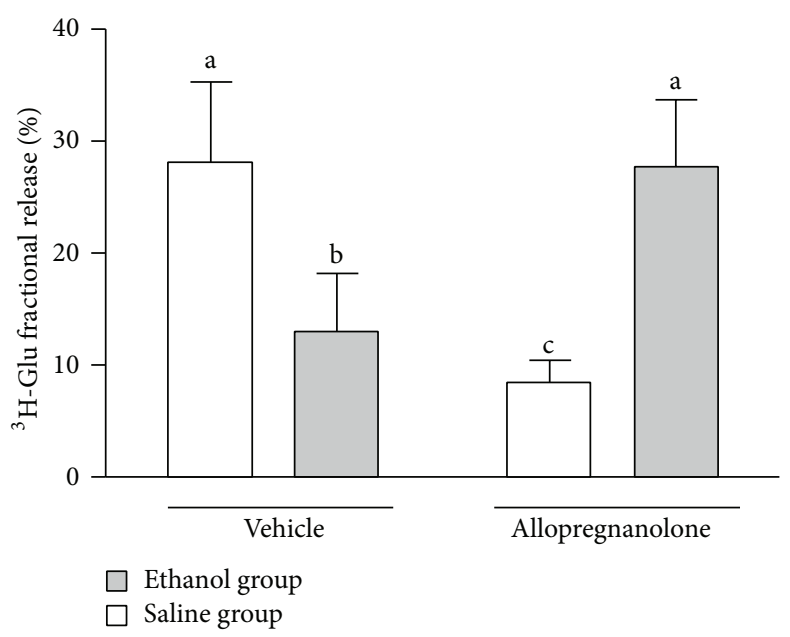

(b)

Figure 1: Panel (a): ${ }^{3} \mathrm{H}$-Glu uptake from rat striatal slices; Panel (b): ${ }^{3} \mathrm{H}$-Glu fractional release induced from rat striatal slices by $28 \mathrm{mM} \mathrm{K}^{+}$. Control (white bars) or prenatal ethanol-exposed (gray bars) male rats were injected with allopregnanolone ( $65 \mu \mathrm{g} / \mathrm{kg}$ ) or vehicle on P21, $2.5 \mathrm{~h}$ before the experiment. Results are expressed as mean \pm SEM $(n=6-9)$ (different letters indicate statistically significant differences).

collected fractions and tissue samples was determined, and the percentage of stimulus-evoked release of ${ }^{3} \mathrm{H}$-Glu or ${ }^{3} \mathrm{H}-$ GABA was calculated as the percentage of increase over baseline after stimulation [22].

2.5. ELISA Assays. ELISA assessments for brain-derived neurotrophic factor (BDNF) were performed using BDNF Emax ImmunoAssay System kits from Promega (Madison, WI, USA). Neurotrophin protein content of striatum was obtained from 4-5 rats. Each ELISA 96-well plate was coated with anti-BDNF monoclonal antibody $(1: 1000$; $100 \mu \mathrm{L} /$ well $)$ in carbonate coating buffer $(0.05 \mathrm{M}$ sodium bicarbonate/carbonate; $\mathrm{pH}$ 9.7). The wells were sealed with a plate sealer and incubated overnight at $4^{\circ} \mathrm{C}$. On the following day, the content of the wells was removed and the plates were washed with Tris-buffered saline with Tween (TBST; $20 \mathrm{mM}$ Tris-HCl, pH 7.6; $150 \mathrm{mM} \mathrm{NaCl}$; 0.05\% v/v Tween-20). Thereafter they were incubated at room temperature (RT) for $1 \mathrm{~h}$ in block and sample buffer (BSB, $200 \mu \mathrm{L} /$ well). Tissue samples were weighed, homogenized in 1:50 Dulbecco's phosphate-buffered saline (DPBS; $\mathrm{pH}$ 7.35), and centrifuged for $15 \mathrm{~min}(13000 \mathrm{rpm})$. Two columns on the ELISA plates were designated for the neurotrophin standard curve, which ranged from 0 to $500 \mathrm{pg} / \mathrm{mL}$. A $200 \mu \mathrm{L}$ aliquot of the tissue sample was added to a well and 3 successive 1:2 dilutions were made. Samples and standards were incubated for 6 hours, washed, and then incubated overnight at $4^{\circ} \mathrm{C}$ with antiNGF or anti-BDNF antibodies. At the end of the procedure, plates were washed and incubated with an anti-rat IgG-HRP conjugate for $2.5 \mathrm{~h}$ at RT. After the incubation, TMB one solution (tetramethylbenzidine and the peroxidase substrate) was added to each well, and the plates were shaken for 5-10 $\mathrm{min}$ at RT; the reaction was terminated by adding $1 \mathrm{~N} \mathrm{HCl}$ to the wells. The plates were read at $450 \mathrm{~nm}$ using a monochromator microplate reader (Safire 2 Team), and the results were normalized per gram of tissue assayed [23].
2.6. Statistical Analyses. Data were expressed as the mean \pm SEM and analyzed using a two-way analysis of variance parametric test (ANOVA 2), followed by a post hoc test whenever necessary (Newman-Keuls test). $P<0.05$ was considered as the minimum criterion for assigning statistical significance.

\section{Results}

3.1. The Effect of Allopregnanolone on Striatal ${ }^{3} \mathrm{H}$-Glutamate Uptake and Release in Male Rats Prenatally Exposed to Ethanol. As an index of the activity of the glutamatergic neurons, induced by prenatal ethanol treatment and acute postnatal pharmacological treatment with allopregnanolone we measured changes in the uptake and release of glutamic acid from corpus striatum slices obtained from the animals that received or did not receive prenatal ethanol. No change in striatal ${ }^{3} \mathrm{H}$-Glu uptake was observed after prenatal exposure to ethanol (Figure 1(a)). On the other hand, both control and prenatal ethanol-exposed rats injected s.c. with 5 allopregnanolone decreased the ${ }^{3} \mathrm{H}$-Glu uptake $(P<0.05)$ in relation to the vehicle injection alone (Figure 1(a)). A clear decrease of ${ }^{3} \mathrm{H}$-Glu release was found in response to the depolarizing stimulus in the prenatal ethanol-exposed rats (Figure 1(b)). The injection of allopregnanolone significantly decreased the stimulus-evoked release of ${ }^{3} \mathrm{H}$-Glu in control rats $(P<$ 0.01 ). Interestingly, the opposite trend is observed in the prenatal ethanol-exposed rats injected with allopregnanolone (Figure 1(b)).

3.2. The Effect of Allopregnanolone on Striatal ${ }^{3} \mathrm{H}-\mathrm{GABA}$ Uptake and Release in Male Rats Prenatally Exposed to Ethanol. As an index of the activity of the GABAergic neurons, induced by prenatal ethanol treatment and acute postnatal pharmacological treatment with allopregnanolone, 


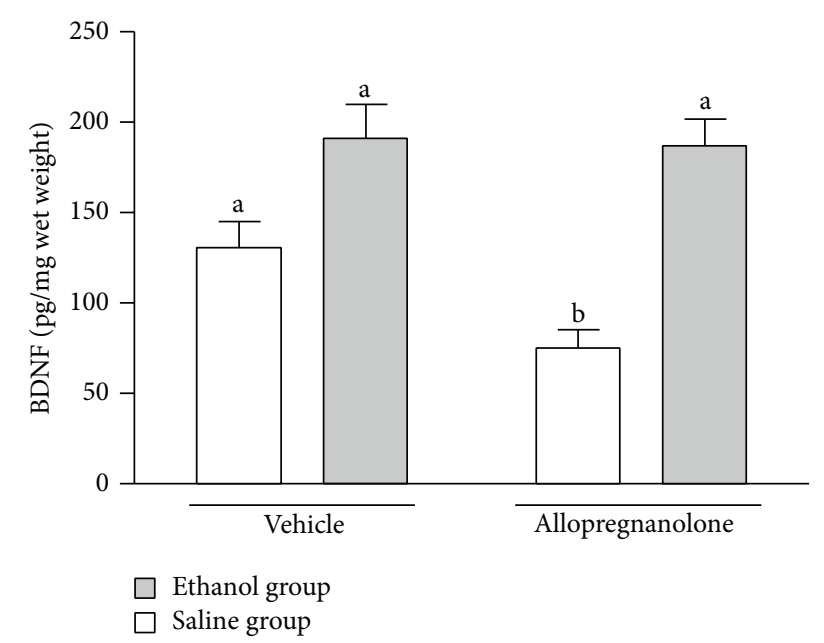

FIGURE 2: Effect of allopregnanolone ( $65 \mathrm{ug} / \mathrm{kg}$ ) on BDNF content in P21 rat striatum. Control (white bars) or prenatal ethanol-exposed (gray bars) male rats were injected with allopregnanolone or vehicle on P21, $2.5 \mathrm{~h}$ before the experiment. Results are expressed as mean \pm SEM $(n=4-5)$ (different letters indicate statistically significant differences).

we measured changes in the uptake and release of GABA from corpus striatum slices obtained from the animals that received or did not receive prenatal ethanol. ${ }^{3} \mathrm{H}-\mathrm{GABA}$ uptake did not change under different experimental conditions. Also, no changes in striatal ${ }^{3} \mathrm{H}-\mathrm{GABA}$ stimulus-evoked release were found after exposure to ethanol or after acute allopregnanolone administration to the rats.

\subsection{The Effect of Allopregnanolone on BDNF Concentrations} in Prenatally Ethanol-Exposed Rat Brain. As an index of neurotrophin participation in the changes of the activity of glutamatergic neurons induced by prenatal ethanol and by allopregnanolone administration, we measured the changes in BDNF protein content in brain tissues that are known to have the receptors for these neurotrophins. Allopregnanolone significantly decreased BDNF levels in striatum of control rats $(P<0.05)$ but not in ethanol-exposed rats (Figure 2$)$.

\section{Discussion}

Herein we report that in control rats the administration of allopregnanolone in a single subcutaneous dose decreases the $\mathrm{K}^{+}$-induced release of glutamate from corpus striatum slices in vitro (Figure $1(\mathrm{~b})$ ) and decreases the BDNF protein content in this structure (Figure 2). Since our subjects were studied just 2.5 hours after injection of allopregnanolone, we think this could represent a rapid agonistic effect on $\mathrm{GABA}_{\mathrm{A}}$ membrane receptors coupled to ionic channels [13,24]. The uptake of glutamate was also decreased by allopregnanolone in the striatum of control animals (Figure 1). Both glutamate uptake and release decrement by allopregnanolone administration, as well as the decrease in the BDNF content in the striatum, could be due to an inhibitory effect of the neurosteroid on the glutamatergic corticostriatal pathway [25-28]. If so, it is possible to speculate that the decrease in the striatal content of the neurotrophin could be a consequence of GABAergic activation by allopregnanolone in control animals.

Prenatal administration of ethanol shows that acute intoxication during GD8 induced long-term changes in the CNS of the offspring [19]. In this work a similar procedure was effective in blocking allopregnanolone action on both glutamate release and BDNF lowering (Figures 1(b) and 2). Allopregnanolone also failed to inhibit the ${ }^{3} \mathrm{H}-\mathrm{GABA}$ release from striatal interneuron, which expresses $\mathrm{GABA}_{\mathrm{A}}$ receptors, in ethanol-treated rats. In addition to the mechanism described above, this observation could be explained by a functional alteration of $\mathrm{GABA}_{\mathrm{A}}$ receptors induced by prenatal ethanol treatment [8]. This suggestion is based on behavioral data pointing out that prenatal exposure to ethanol can alter the $\mathrm{GABA}_{\mathrm{A}}$ sensitivity to the modulatory effects of allopregnanolone $[8,29,30]$. Furthermore, it was reported that prenatal exposure to ethanol can produce long-lasting alterations in the neuromodulatory influences on $\mathrm{GABA}_{\mathrm{A}}$ receptor-mediated transmission, as a consequence of either differential $\mathrm{GABA}_{\mathrm{A}}$ receptor subunit expression or receptor uncoupling [31,32]. Thus, ethanol-induced alterations in $\mathrm{GABA}_{\mathrm{A}}$ subunits expressed in the prefrontal cortex may play a role in the observed modulatory responses to allopregnanolone. It is possible that both of these mechanisms, one as a preferential action of allopregnanolone at cortical level and the other affecting the expression of $\mathrm{GABA}_{\mathrm{A}}$ receptor subunits, may contribute to allopregnanolone effects on glutamate release in ethanol-exposed rats. Since allopregnanolone did not modify striatal BDNF content in these rats, it might also contribute to restoring the excitatory tone toward normal values. Whether or not these modifications are persistent is an issue to be elucidated in the near future.

Altogether the data reported here show that a single dose of allopregnanolone administrated to control rats inhibited excitatory neurotransmission and decreased BDNF protein content at corpus striatum. Ethanol exposure in utero may produce alterations in $\mathrm{GABA}_{\mathrm{A}}$ receptors that could explain the rapid modification in glutamate release and the synthesis and/or secretion of cortical BDNF. Thus, the effects of alcohol on $\mathrm{GABA}_{\mathrm{A}}$ receptors may induce the trophic and regulatory actions of neurotrophins. Moreover, interactions between endogenous GABAergic-like neurosteroids such as allopregnanolone and certain neurotrophins could underlie mechanisms operating within the brain's developmental plasticity, giving protection of the fetus against insults such as ethanol prenatal exposure.

\section{Conflict of Interests}

The authors declare that there is no conflict of interests regarding the publication of this paper.

\section{Acknowledgments}

The work was supported by grants from the National Research Council of Argentina CONICET (PIP 11220100100126), Universidad de Mendoza (133/10), and Fondecyt 102-0581. 


\section{References}

[1] C. R. Goodlett and K. H. Horn, "Mechanisms of alcoholinduced damage to the developing nervous system," Alcohol Research and Health, vol. 25, no. 3, pp. 175-184, 2001.

[2] J. W. Olney, "Fetal alcohol syndrome at the cellular level," Addiction Biology, vol. 9, no. 2, pp. 137-149, 2004.

[3] M. P. Aronne, T. Guadagnoli, P. Fontanet, S. G. Evrard, and A. Brusco, "Effects of prenatal ethanol exposure on rat brain radial glia and neuroblast migration," Experimental Neurology, vol. 229, no. 2, pp. 364-371, 2011.

[4] A. E. Medina, "Fetal alcohol spectrum disorders and abnormal neuronal plasticity," Neuroscientist, vol. 17, no. 3, pp. 274-287, 2011.

[5] A. Nardelli, C. Lebel, C. Rasmussen, G. Andrew, and C. Beaulieu, "Extensive deep gray matter volume reductions in children and adolescents with fetal alcohol spectrum disorders," Alcoholism: Clinical and Experimental Research, vol. 35, no. 8, pp. 1404-1417, 2011.

[6] F. F. Roussotte, K. K. Sulik, S. N. Mattson et al., "Regional brain volume reductions relate to facial dysmorphology and neurocognitive function in fetal alcohol spectrum disorders," Human Brain Mapping, vol. 33, no. 4, pp. 920-937, 2012.

[7] M. B. Heaton, J. J. Mitchell, M. Paiva, and D. W. Walker, "Ethanol-induced alterations in the expression of neurotrophic factors in the developing rat central nervous system," Developmental Brain Research, vol. 121, no. 1, pp. 97-107, 2000.

[8] R. Zhou, S. Wang, and X. Zhu, "Prenatal ethanol exposure attenuates GABAergic inhibition in basolateral amygdala leading to neuronal hyperexcitability and anxiety-like behavior of adult rat offspring," Neuroscience, vol. 170, no. 3, pp. 749-757, 2010.

[9] K. Hirani, A. N. Sharma, N. S. Jain, R. R. Ugale, and C. T. Chopde, "Evaluation of GABAergic neuroactive steroid $3 \alpha$ hydroxy- $5 \alpha$ - pregnane-20-one as a neurobiological substrate for the anti-anxiety effect of ethanol in rats," Psychopharmacology, vol. 180, no. 2, pp. 267-278, 2005.

[10] R. T. Khisti, S. N. Penland, M. J. Vandoren, A. C. Grobin, and A. L. Morrow, "GABAergic neurosteroid modulation of ethanol actions," The World Journal of Biological Psychiatry, vol. 3, no. 2, pp. 87-95, 2002.

[11] D. S. Reddy, "Role of anticonvulsant and antiepileptogenic neurosteroids in the pathophysiology and treatment of epilepsy," Frontiers in Endocrinology, vol. 2, article 38, 2011.

[12] D. H. Kim, J. M. Kim, S. J. Park et al., "GABA a receptor blockade enhances memory consolidation by increasing hippocampal BDNF levels," Neuropsychopharmacology, vol. 37, no. 2, pp. 422433, 2012.

[13] R. C. Melcangi, G. Panzica, and L. M. Garcia-Segura, "Neuroactive steroids: Focus on human brain," Neuroscience, vol. 191, pp. $1-5,2011$.

[14] J. B. Cook, A. M. G. Dumitru, T. K. O’Buckley, and A. L. Morrow, "Ethanol administration produces divergent changes in GABAergic neuroactive steroid immunohistochemistry in the rat brain," Alcoholism: Clinical and Experimental Research, vol. 38, no. 1, pp. 90-99, 2014.

[15] J. J. Mitchell, M. Paiva, D. W. Walker, and M. B. Heaton, "BDNF and NGF afford in vitro neuroprotection against ethanol combined with acute ischemia and chronic hypoglycemia," Developmental Neuroscience, vol. 21, no. 1, pp. 68-75, 1999.

[16] M. Singh and C. Su, "Progesterone, brain-derived neurotrophic factor and neuroprotection," Neuroscience, vol. 239, pp. 84-91, 2013.
[17] S. Fulginiti, J. Artinian, R. Cabrera, and P. Contreras, "Response to an ethanol challenge dose on sleep time and blood alcohol level in Wistar rats prenatally exposed to ethanol during gestational day 8," Alcohol, vol. 6, no. 3, pp. 253-256, 1989.

[18] J. Gil-Mohapel, F. Boehme, L. Kainer, and B. R. Christie, "Hippocampal cell loss and neurogenesis after fetal alcohol exposure: insights from different rodent models," Brain Research Reviews, vol. 64, no. 2, pp. 283-303, 2010.

[19] J. C. Molina, H. F. Moyano, L. P. Spear, and N. E. Spear, "Acute alcohol exposure during gestational day 8 in the rat: effects upon physical and behavioral parameters," Alcohol, vol. 1, no. 6, pp. 459-464, 1984.

[20] Institute of Laboratory Animal Research, Commission on Life Sciences, and National Research Council, Guide for the Care and Use of Laboratory Animals, The National Academic Press, New York, NY, USA, 1996.

[21] C. A. Frye, J. J. Paris, and M. E. Rhodes, "Increasing $3 \alpha, 5 \alpha-$ THP following inhibition of neurosteroid biosynthesis in the ventral tegmental area reinstates anti-anxiety, social, and sexual behavior of naturally receptive rats," Reproduction, vol. 137, no. 1, pp. 119-128, 2009.

[22] R. J. Cabrera and C. Bregonzio, "Turnover rate and stimulusevoked release of dopamine by progesterone and $\mathrm{N}$-methylD-aspartic acid in rat striatum during pregnancy," European Journal of Pharmacology, vol. 317, no. 1, pp. 55-59, 1996.

[23] H. Yu, D.-D. Wang, Y. Wang, T. Liu, F. S. Lee, and Z.-Y. Chen, "Variant brain-derived neurotrophic factor Val66met polymorphism alters vulnerability to stress and response to antidepressants," The Journal of Neuroscience, vol. 32, no. 12, pp. 4092-4101, 2012.

[24] H. M. Park, I. S. Choi, M. Nakamura, J. H. Cho, M. G. Lee, and I. S. Jang, "Multiple effects of allopregnanolone on GABAergic responses in single hippocampal CA3 pyramidal neurons," European Journal of Pharmacology, vol. 652, no. 1-3, pp. 46-54, 2011.

[25] C. Anthony Altar, N. Cai, T. Bliven et al., "Anterograde transport of brain-derived neurotrophic factor and its role in the brain," Nature, vol. 389, no. 6653, pp. 856-860, 1997.

[26] C. A. Altar and P. S. DiStefano, "Neurotrophin trafficking by anterograde transport," Trends in Neurosciences, vol. 21, no. 10, pp. 433-437, 1998.

[27] Y. Xie, M. R. Hayden, and B. Xu, "BDNF overexpression in the forebrain rescues Huntington's disease phenotypes in YAC128 mice," Journal of Neuroscience, vol. 30, no. 44, pp. 14708-14718, 2010.

[28] G. Naert, T. Maurice, L. Tapia-Arancibia, and L. Givalois, "Neuroactive steroids modulate HPA axis activity and cerebral brain-derived neurotrophic factor (BDNF) protein levels in adult male rats," Psychoneuroendocrinology, vol. 32, no. 8-10, pp. 1062-1078, 2007.

[29] B. Zinimerberg, "Differential behavioral effects of the neuroactive steroid allopregnanolone on neonatal rats prenatally exposed to alcohol," Pharmacology Biochemistry and Behavior, vol. 51, no. 2-3, pp. 463-468, 1995.

[30] B. Zimmerberg and R. C. Brown, "Prenatal experience and postnatal stress modulate the adult neurosteroid and catecholaminergic stress responses," International Journal of Developmental Neuroscience, vol. 16, no. 3-4, pp. 217-228, 1998.

[31] A. M. Allan, H. Wu, L. L. Paxton, and D. D. Savage, "Prenatal ethanol exposure alters the modulation of the $\gamma$-aminobutyric 
acid(A) receptor-gated chloride ion channel in adult rat offspring," The Journal of Pharmacology and Experimental Therapeutics, vol. 284, no. 1, pp. 250-257, 1998.

[32] L. Toso, R. Roberson, J. Woodard, D. Abebe, and C. Y. Spong, "Prenatal alcohol exposure alters GABA(A)alpha5 expression: a mechanism of alcohol-induced learning dysfunction," The American Journal of Obstetrics and Gynecology, vol. 195, no. 2, pp. 522-527, 2006. 

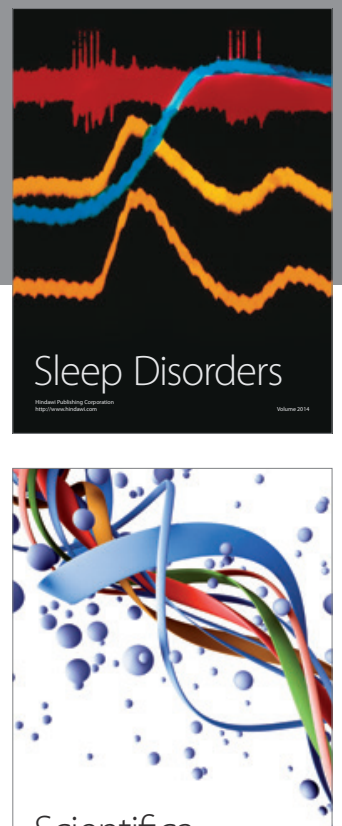

Scientifica
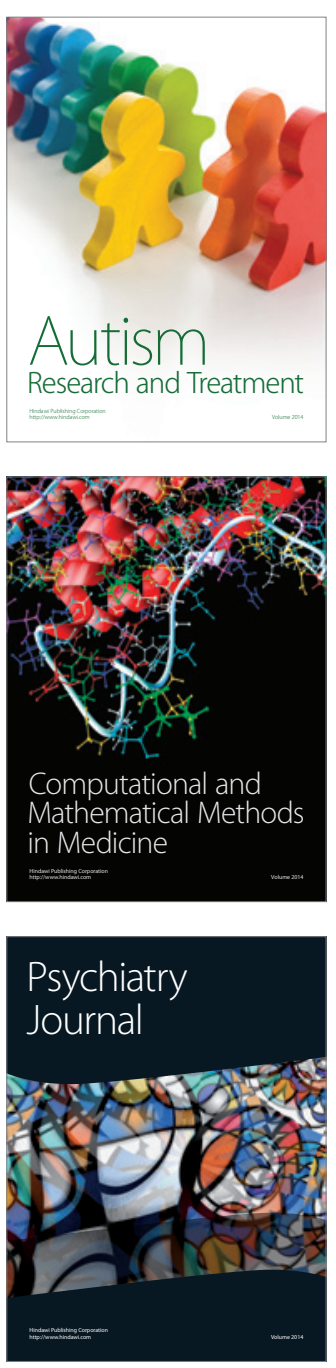
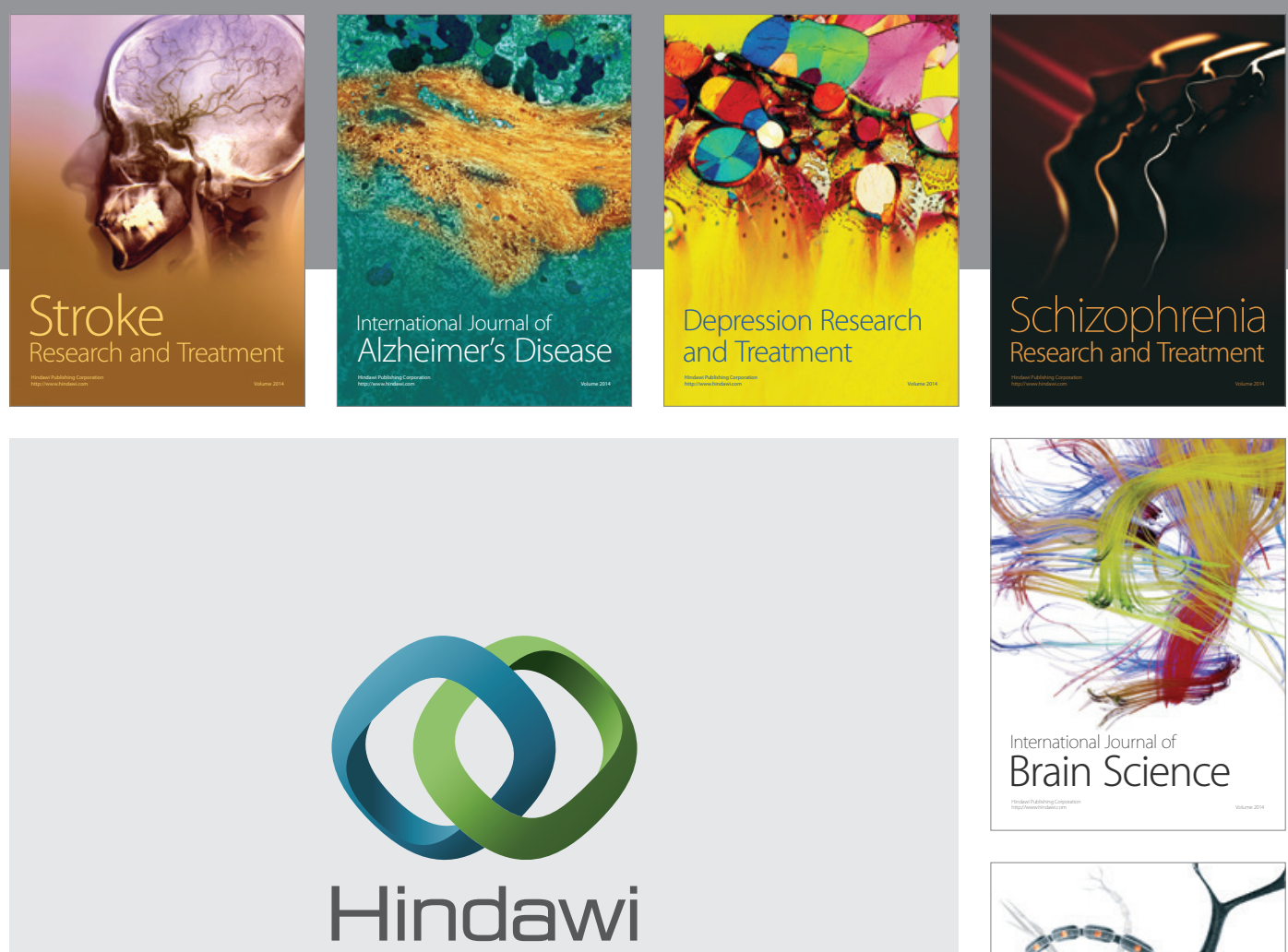

Submit your manuscripts at

http://www.hindawi.com
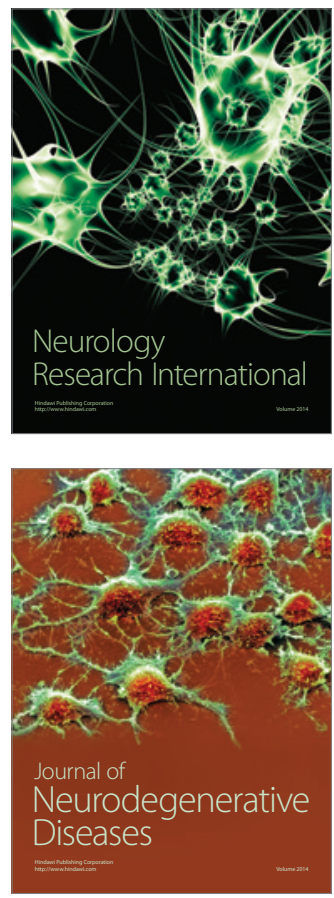

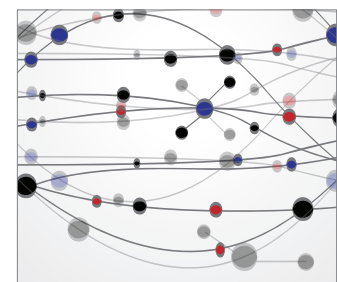

The Scientific World Journal
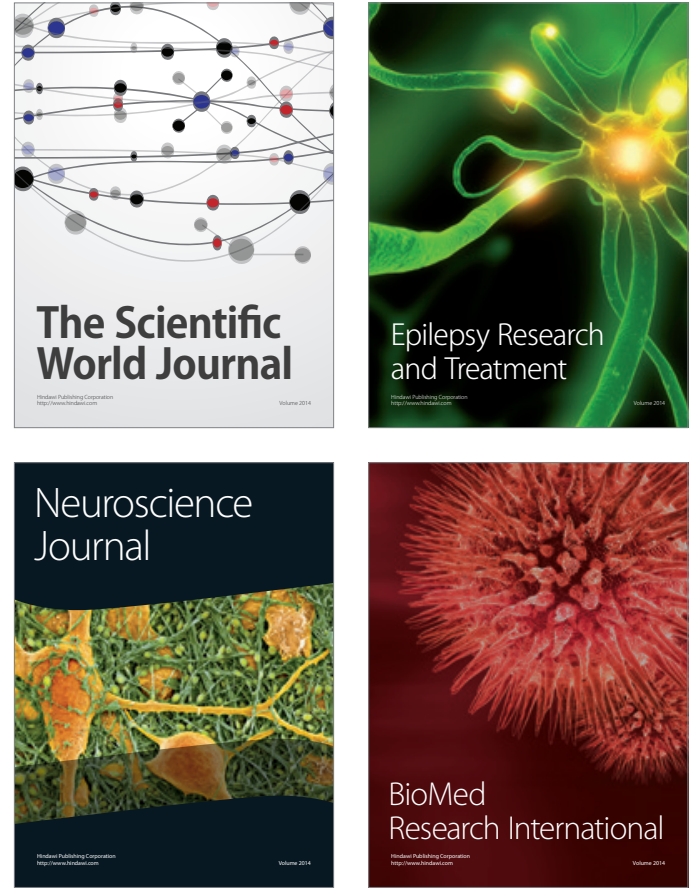

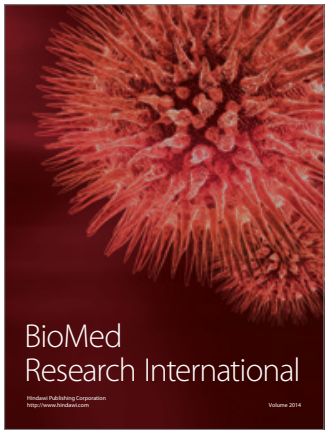

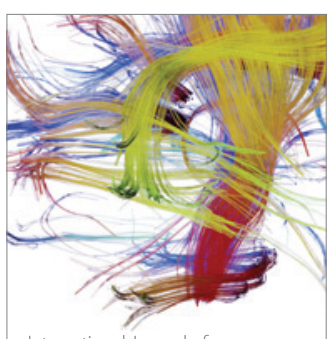

Brain Science

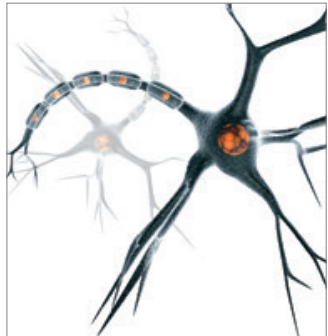

Neural Plasticity
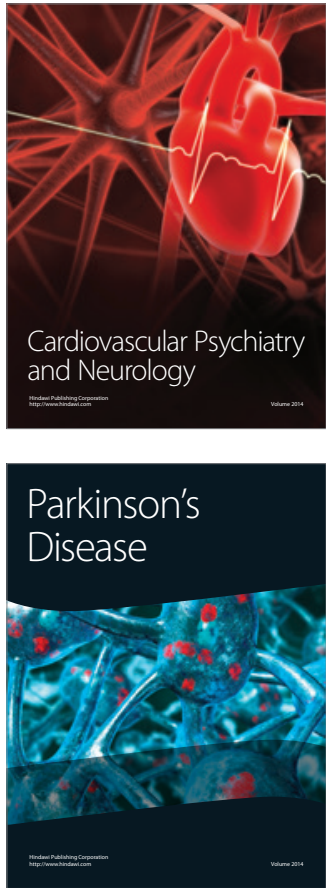